\title{
CONSTITUIÇÃO, EPISTEMOLOGIA E DECISÃO JUDICIAL: A NECESSIDADE DE CONSTRUÇÃO DE UM MODELO NORMATIVO DE FUNDAMENTAÇÃO DO JUÍZO DE FATO
}

\author{
Angélica Mota Cabral ${ }^{1}$ \\ Gabriela Pimentel Pessoa ${ }^{2}$
}

Resumo: A Constituição de 1.988 impõe o dever de fundamentação das decisões judiciais, inclusive do convencimento do juiz sobre fatos relevantes, sendo a fundamentação do juízo de fato o ponto de interseção entre a teoria da decisão judicial e a teoria da prova. Apesar disso, não há qualquer previsão normativa acerca dos requisitos mínimos para fundamentação do juízo de fato. Propõe-se o desenvolvimento de um modelo normativo de fundamentação do juízo de fato a partir do estudo das teorias epistemológicas de justificação epistêmica, superando-se, através do diálogo entre Direito e Epistemologia, as deficiências da disciplina do convencimento judicial sobre fatos relevantes.

Palavras-chave: decisão judicial; juízo de fato; fundamentação da decisão judicial; epistemologia; justificação epistêmica.

\section{CONSTITUTION, EPISTEMOLOGY AND JUDICIAL DECISION: THE NEED TO CREATE A NORMATIVE MODEL FOR REASONING JUDICIAL DECISIONS ABOUT FACTS}

\begin{abstract}
The Constitution of 1988 imposes the duty to justify judicial decisions, including the conviction of the judge on relevant facts, and state reason for facts is the point of intersection between the theory of judicial decision and the theory of proof. Despite this, there is no normative prediction about the minimum requirements for reasoning about facts. It proposes the development of a normative model of the foundation of the de jure, based on the study of the epistemological theories of epistemic justification, overcoming, through the dialogue between Law and Epistemology.
\end{abstract}

Keywords: procedural law; judicial decision about facts; legal reasoning; epistemic justification; epistemology.

\section{INTRODUÇÃO}

\footnotetext{
${ }^{1}$ Mestranda pelo Programa de Pós-Graduação da Universidade Federal do Ceará (UFC). Membro da Associação Brasileira de Direito Processual (ABDPro) e da Diretoria da Comissão de Direito Processual da OAB-CE. Professora da pós-graduação em Direito Processual Civil.

2 Doutora em Direito pela Universidade Federal do Rio Grande do Sul (UFRGS). Mestre em Direito pela Universidade Federal do Ceará (UFC). Advogada especialista em Família e Sucessões. Professora de Direito de Família do Centro Universitário Estácio do Ceará.
} 
É amplamente reconhecido o papel primordial da fundamentação das decisões judiciais em um Estado Democrático de Direito. É através da obrigatória fundamentação das decisões judiciais que diversos dos valores constitucionais relativos ao processo judicial podem alcançar sua realização concreta, como, por exemplo, o contraditório, o princípio da legalidade, a imparcialidade do juiz, entre outros.

A Constituição Federal de 1.988 impõe explicitamente o dever de fundamentação das decisões judiciais, podendo-se concluir que assegurar a racionalidade destas é um objetivo crucial do Estado Democrático de Direito. Nesse sentido, pode-se afirmar que um dos maiores desafios da ciência jurídica contemporânea consiste no estabelecimento de critérios objetivos com base nos quais se possa avaliar se determinada decisão é ou não racional - ou seja, se atende ou não ao comando veiculado na norma contida no art. 93, IX da CF.

É de ampla sabença a relação entre normas e fatos, de um lado, e a relação entre atuação jurisdicional e normas, por outro. Tais relações tornam compreensível a razão pela qual o juiz deve admitir certos fatos como tendo ocorrido ou não e quais fatos seriam esses. É certo que há uma grande diversidade de situações a dificultar a adoção de um esquema único de análise para as relações entre fatos, normas e decisão judicial. Por isso mesmo, sempre existirão casos periféricos, mas não menos importantes, onde a determinação acerca de quais fatos devem ser levados em consideração pelo juiz, como condição necessária de sua atuação jurisdicional, não se enquadra em qualquer esquema primário que venha a ser adotado, mesmo por que o sistema do livre convencimento motivado é considerado insuficiente para a fundamentação da decisão em matéria de fato.

De toda forma, sabe-se que as normas estatais - sejam as prescritivas, sejam as que conferem poderes - condicionam a sua incidência concreta à ocorrência de determinados fatos, descritos nas próprias normas. Assim, por exemplo, quando um juiz é convocado a declarar a existência ou não de um direito subjetivo, ou seja, naquelas situações em que a sua atuação jurisdicional consiste em proferir uma declaração nesse sentido, ele deve se posicionar sobre a ocorrência ou não dos chamados "fatos constitutivos do direito", vale dizer, os fatos previstos na norma que assegura o direito subjetivo, como condição de sua incidência concreta.

Como se vê, em todas essas circunstâncias, é em razão da própria estrutura das normas jurídicas e do papel desempenhado por essas normas na função jurisdicional, que o juiz deve, como condição indispensável de sua atuação jurisdicional, formar um 


\section{CONSTITUIÇÃO, EPISTEMOLOGIA E DECISÃO JUDICIAL: A NECESSIDADE DE CONSTRUÇÃO DE UM MODELO NORMATIVO DE FUNDAMENTAÇÃO DO JUÍZO DE FATO}

convencimento (formar deliberadamente uma crença) sobre a ocorrência ou não de determinados fatos, mais precisamente os fatos descritos na norma como condição da incidência concreta delas.

Esses fatos, que podem ser denominados fatos primariamente relevantes, são aqueles sobre cuja ocorrência o juiz deve formar um convencimento. Diz-se que estes fatos são primariamente relevantes porque há outros fatos sobre a ocorrência dos quais o juiz também deve formar convencimento, como etapa do processo lógico de formação de seu convencimento sobre fatos primariamente relevantes. Aos fatos deste segundo grupo, convém denominar fatos secundariamente relevantes.

O presente artigo tem como objetivo demonstrar que, na medida em que o juízo de fato constitui parte importantíssima da decisão judicial, a ausência de fundamentação sobre tais juízos constitui um descumprimento da norma constitucional que determina a fundamentação da decisão judicial.

Só por essa razão, já se pode compreender que o convencimento judicial sobre os fatos primários deve ser fundamentado. Nenhuma decisão pode ter como fundamento uma premissa que não seja, por sua vez, fundamentada. Dessa forma, parte indispensável da fundamentação das decisões judiciais, cuja obrigatoriedade é imposta, como se sabe, no art. 93, IX, da CF, vem a ser aquela destinada a fundamentar o convencimento do juiz sobre os fatos relevantes, ou seja, a fundamentação do juízo de fato. Este vem a ser o ponto de interseção entre a teoria da decisão judicial e a teoria da prova judicial.

Por um lado, há uma total ausência de previsão normativa acerca de requisitos mínimos para fundamentação do juízo de fato, bem como um deficitário tratamento da temática na própria doutrina processual brasileira. Por outro lado, a Epistemologia exsurge como "fonte" de subsídios capaz de sanar essas deficiências da disciplina jurídica relativa à formação racional do convencimento judicial sobre fatos relevantes.

Assim, conclui-se que deve ser desenvolvido um modelo normativo de fundamentação do juízo de fato a partir do estudo das teorias epistemológicas de justificação epistêmica, superando-se, através do diálogo entre Direito e Epistemologia, as deficiências da disciplina jurídica do convencimento judicial sobre fatos relevantes.

\section{FATOS, MEIOS DE PROVA E ARBÍTRIO NA FUNDAMENTAÇÃO DO JUÍZO DE FATO}

Rev. de Teorias da Justiça, da Decisão e da Argumentação Jurídica | e-ISSN: 2525-9644 | Porto Alegre | v. 4 | n. 2 | p. 71 - 87 | Jul/Dez. 2018 
O termo "fato jurídico" não é unívoco na linguagem jurídica. Muitas discussões já surgiram em torno de sua definição. A enciclopédia jurídica italiana explica que há pelo menos dois sentidos diversos do termo que podem ser apontados: fato jurídico significando aquilo que uma norma jurídica correlaciona a um feito jurídico; e fato jurídico para significar o evento não identificado como "ato", isto é, todos os fenômenos temporais não configurados como atividade humana voluntária.

A teoria do fato jurídico construída por Pontes Miranda é bastante particular e difundida. $\mathrm{O}$ autor afirma que a regra jurídica, enquanto proposição, prevê fatos de possível ocorrência no mundo. Dá-se o nome de suporte fático ao fato ou conjunto de fatos previstos abstratamente. Quando o que está previsto na norma acontece, no plano da experiência, dá-se a incidência, de modo que o fato passa a ser considerado jurídico. Composto o fato jurídico, surgem, no mundo jurídico, os efeitos previstos em abstrato na norma. Segundo Miranda (1954, p. 4),

\footnotetext{
"Os elementos do suporte fático são pressupostos do fato jurídico; o fato jurídico é o que entra, do suporte fáctico, no mundo jurídico, mediante a incidência da regra jurídica sobre o suporte. Só de fatos jurídicos provêem a eficácia jurídica.”
}

A partir da ideia de fato jurídico como produto da incidência da norma jurídica sobre seu suporte fático, ocorreria a separação do mundo dos fatos do mundo jurídico.

Entretanto, é necessário considerar que, conforme Taruffo (2012, p. 235), um fato jamais é uma entidade simples e homogênea, passível de ser definido de modo exaustivo através de um enunciado do tipo "x existe"; cada fato, portanto, pode ser narrado em uma infinita variedade de modos, dependendo das circunstância levadas em consideração e dos diferentes pontos de vista a partir dos quais o fato é descrito.

Em termos amplos, a função dos meios de prova no processo civil pode ser definida com bastante facilidade em todos os sistemas processuais. De maneira mais ou menos clara, os meios de prova conectam-se aos fatos em litígio através de uma relação instrumental: meio de prova é qualquer elemento que possa ser utilizado para estabelecer a verdade dos fatos da causa, a função principal da prova é oferecer ao julgador informação confiável acerca da verdade dos fatos em litígio. Segundo Taruffo (2014, p. 15):

\footnotetext{
Tem-se que a ideia básica é que um litígio surge a partir de certos fatos e sobre esses se baseia; que esses são fatos são disputados pelas partes; que tal disputa deve ser resolvida pelo tribunal, e que a solução da controvérsia sobre os fatos é
} 


\section{CONSTITUIÇÃO, EPISTEMOLOGIA E DECISÃO JUDICIAL: A NECESSIDADE DE CONSTRUÇÃO DE UM MODELO NORMATIVO DE FUNDAMENTAÇÃO DO JUÍZO DE FATO}

alcançada quando o tribunal estabelece a verdade sobre os fatos que motivaram a disputa.

É importante observar que os fatos não se incorporam nos procedimentos judiciais na sua realidade empírica ou material, pois, em geral, os fatos já ocorreram e pertencem, portanto, ao passado. Consequentemente, salvo alguns elementos circunstanciais, os fatos não podem ser percebidos pelo juiz, devendo ser reconstruídos pelo julgador com base na prova disponível. Fatos, então, segundo Taruffo (2014, p. 19), são tomados em consideração de uma forma muito peculiar, isto é, na forma de enunciados acerca do que ocorreu faticamente, de forma que, quando se fala em verdade de um fato, na realidade fala-se da verdade de um enunciado acerca desse fato.

Isso quer dizer que, no início de um procedimento, os fatos se apresentam na forma de enunciados de fato caracterizados pelo que Taruffo (2014, p. 129) chama de "status epistêmico da incerteza". Portanto, decidir sobre fatos significa ultrapassar tal "status" e resolver a incerteza, determinando, a partir dos meios de prova, se os enunciados iniciais se provaram verdadeiros ou falsos. Produzidas todas as provas admissíveis, chega-se no momento do procedimento de proferir a decisão acerca dos enunciados de fato, resolvendo-se a incerteza e estabelecendo o que foi considerado verdadeiro.

Ocorre que chegar a essa demonstração dos fatos pode ter diferentes graus de complexidade, variando de acordo com as características específicas de cada caso concreto, com a instrução processual realizada, ou seja, com o meios de prova utilizados, a quantidade e a qualidade e, sem dúvida, com a natureza dos fatos que necessitam de determinação. De fato, embora possam existir casos simples, a maior parte dos considerados casos difíceis são assim considerados por que as questões de fato a eles relacionadas são difíceis de resolver, contando com provas complexas e/ou incertas.

Em se estabelecendo que em razão da estrutura das normas jurídicas e da vinculação à lei que marca a atuação jurisdicional, o juiz deve se convencer acerca da ocorrência ou não de certos fatos, é imperioso reconhecer que tal convencimento do juiz acerca de fatos relevantes constituirá, necessariamente, um dos fundamentos da própria decisão judicial que o juiz é chamado a proferir. Tomando mais uma vez o exemplo da declaração judicial sobre existência ou não de certo direito subjetivo, pois a ocorrência ou não do fato constitutivo é determinante para a decisão sobre a existência do direito, esta decisão deverá ser fundamentada, entre outras coisas, no convencimento do juiz sobre isso. Assim, a decisão 
sobre a existência do direito deverá ter como fundamento a convicção do juiz sobre a ocorrência do fato constitutivo.

O fato é que, qualquer que seja o caso, não há, no atual regramento normativo processual brasileiro, qualquer parâmetro que oriente o juiz na utilização das provas no que pertine à fundamentação dos juízos de fato, gerando, por consequência, decisões deficientemente fundamentadas ou mesmo completamente carentes de fundamentação sobre tal aspecto inextrincável do processo, violando a norma constitucional pertinente à fundamentação das decisões judiciais. Tal estado de coisas gera anomalias tais como o juiz não poder, por expressa determinação do art. 489 do CPC/2015 (que fixa parâmetros para a fundamentação da decisão no que diz respeito às questões de direito) limitar-se a reproduzir motivos tais que se prestariam a fundamentar qualquer decisão, sem o cotejo com o caso concreto sob exame, mas poder, de outra banda, proferir juízos de fato sem qualquer fundamentação, considerando as provas de acordo com seu arbítrio. Distorções tais parecem estar diretamente relacionadas ao modelo processual do livre convencimento motivado e ao deficitário tratamento dado à temática do juízo de fato no Brasil.

A própria noção de livre convencimento determina ao julgador uma investigação sobre os fatos amparada em critérios epistemológicos. Porém, conforme aponta Silveira (2011), essa estratégia apresenta dificuldades insuperáveis nas diversas formulações desse tipo de raciocínio por não oferecer respostas definitivas para solucionar problemas práticos, como aqueles envolvidos na concretização do direito, levando a graus diferentes de dúvida. Dessa forma, surge o questionamento sobre qual o nível de confirmação será aceito para respaldar uma decisão.

Em se estabelecendo que, em razão da estrutura das normas jurídicas e da vinculação à lei que marca a atuação jurisdicional, o juiz deve se convencer acerca da ocorrência ou não de certos fatos, é imperioso reconhecer que tal convencimento do juiz acerca de fatos relevantes constituirá, necessariamente, um dos fundamentos da própria decisão judicial que o juiz é chamado a proferir. Tomando mais uma vez o exemplo da declaração judicial sobre existência ou não de certo direito subjetivo, pois a ocorrência ou não do fato constitutivo é determinante para a decisão sobre a existência do direito, esta decisão deverá ser fundamentada, entre outras coisas, no convencimento do juiz sobre isso. Assim, a decisão sobre a existência do direito deverá ter como fundamento a convicção do juiz sobre a ocorrência do fato constitutivo. 


\section{CONSTITUIÇÃO, EPISTEMOLOGIA E DECISÃO JUDICIAL: A NECESSIDADE DE CONSTRUÇÃO DE UM MODELO NORMATIVO DE FUNDAMENTAÇÃO DO JUÍZO DE FATO}

Os critérios de suficiência para o juízo de fato operam como topoi para o raciocínio probatório, tendo valor argumentativo para identificar a suficiência da prova. É uma espécie de argumento que busca submeter ao contraditório toda a decisão formulada nesse particular, atribuindo parâmetros para que essa discussão seja travada. Knijinik (2007, p. 46) atribui a esses critérios o papel de viabilizar a correção judicial dos erros cometidos e principalmente evitar que os sujeitos processuais sejam expostos a qualquer forma de arbítrio no terreno probatório e no uso do livre convencimento.

É certo que, ao se tratar do tema da fundamentação judicial, necessariamente deparase com o modelo do livre convencimento motivado, que contaria, segundo a processualística moderna, notadamente para aquela desenvolvida no esteio da tradição europeia continental, com uma acentuada capacidade de conformação harmônica dos institutos da teoria da prova, o que não se coadunaria com a realidade. Segundo Silveira (2011, p. 15), por um lado, a proposta do livre convencimento primeiro justifica sua existência na necessidade romper com a ideia de prova legal, cujo desenvolvimento histórico foi considerado inadequado para a investigação dos fatos. Por outro, procura expressar o que significaria a proposta do livre convencimento, de modo a viabilizar o controle necessário de legitimidade das decisões judiciais sem ceder a arbitrariedades.

O livre convencimento seria, portanto, o sistema mais adequado para a valoração da prova por que equilibraria, com maior possibilidade de êxito, o controle do poder jurisdicional quando da interpretação dos elementos trazidos aos autos e a liberdade de interpretação necessária ao exercício desse poder, o que deixaria os juízes mais capacitados a compreender corretamente a situação de fato. Essa proposta de compreensão da cognição judicial pretende controlar o juízo de fato com uma série de recomendações, dentre as quais pode-se citar, como exemplo, postular inferências somente a partir dos elementos colhidos dos autos, motivar as conclusões que servem de embasamento da decisão em matéria de fato ou considerar, em alguns casos, a prévia valoração da lei para situações do raciocínio probatório, como presunções e regras de exclusão de provas com a condição de serem compatíveis com os pressupostos epistemológicos assumidos. Tais limitações seriam suficientemente aptas ao controle da decisão judicial, pois esta estaria submetida a métodos adequados de análises empíricas que sigam os ditames da mesma concepção de conhecimento racional.

Silveira (2011, p. 20) aponta que, apesar de ter como ponto de partida o entusiasmo com as conquistas epistemológicas, o livre convencimento, de forma paradoxal, deixa de 
considerar o raciocínio empregado na consideração dos fatos. O tratamento sobre a temática se restringe à imposição, pelo legislador, de normas e técnicas para condução da consideração de elementos probatórios, funcionando estritamente na restrição do arbítrio em juízos de fato, especialmente mediante a regulamentação da participação dos interessados no procedimento, o acesso à possibilidade de recursos e duplo grau, a obrigação de motivação das decisões, mas em nenhum momento trata sobre como considerar as provas produzidas.

O modelo do livre convencimento motivado, ao contrário do modelo da prova legal onde há a imposição de regras de constatação dos fatos dissociando a relação entre convencimento e comprovação - deixa ao total arbítrio do magistrado a afirmação de quando um fato está ou não devidamente comprovado. Em geral, há a estipulação de que o julgamento deve se pautar tão somente nas disposições referentes aos ônus da prova, porém, segundo aduz Silveira (2011, p. 26), trata-se de uma imposição artificial de limite contra o contra o arbítrio do juiz, pois, dependendo apenas daquilo que o próprio julgador entenda como necessário à comprovação dos fatos da causa em comparação ao que foi apresentado, incidirá ou não a regra de ônus da prova. Por certo que, com tão ampla margem de liberdade para afirmar quando um fato está ou não provado, a fundamentação acerca dos juízos de fato é praticamente relegada ao esquecimento.

A construção de um modelo normativo para fundamentação do juízo de fato restringe a discricionariedade judicial, no sentido de que deverá haver a necessária fundamentação em relação à cognição judicial dos fatos relevantes.

Por um lado, verifica-se a insuficiência dos elementos normativos para fornecerem os parâmetros mínimos a serem observados na fundamentação do juízo de fato. Observa-se que há diversas normas no ordenamento que, direta ou indiretamente, disciplinam, em algum aspecto, a formação do convencimento judicial. Estas normas compõem, assim, o que se pode denominar disciplina jurídica do convencimento judicial sobre fatos relevantes (o juízo de fato) e deveriam fornecer um modelo normativo de fundamentação do juízo de fato, mas se revelam insuficientes para tanto. Por exemplo, na disciplina jurídica do convencimento judicial não são explicitados critérios objetivos de valoração das provas. Da mesma forma, o problema do grau mínimo de confirmação de um determinado convencimento ou juízo de fato - o problema dos chamados standards probatórios - não recebe nenhum tratamento na mencionada disciplina jurídica. Inexiste tratamento adequado da temática pela doutrina processual brasileira, sendo esta ainda mais deficitária no que diz respeito ao tratamento dos 


\section{CONSTITUIÇÃO, EPISTEMOLOGIA E DECISÃO JUDICIAL: A NECESSIDADE DE CONSTRUÇÃO DE UM MODELO NORMATIVO DE FUNDAMENTAÇÃO DO JUÍZO DE FATO}

aspectos epistemológicos da prova judicial. Visualiza-se que temas referentes aos critérios de valoração das provas, de determinação de standards probatórios a serem observados não se encontram devidamente abordados.

O Código de Processo Civil de 2015 trouxe parâmetros a partir dos quais se pode considerar ou não uma decisão fundamentada do ponto de vista do "direito", ou seja, das questões de direito, de forma que, por exemplo, não se considera fundamentada uma decisão que se limitar à indicação, à reprodução ou à paráfrase de ato normativo, sem explicar sua relação com a causa ou a questão decidida, da mesma forma como não se considera fundamentada uma decisão que empregar conceitos jurídicos indeterminados, sem explicar o motivo concreto de sua incidência no caso ou, ainda, uma decisão que invoque motivos que se prestariam a justificar qualquer outra decisão ou que não enfrentar todos os argumentos deduzidos no processo capazes de, em tese, infirmar a conclusão adotada pelo julgado, limitar-se a invocar precedente ou enunciado de súmula, sem identificar seus fundamentos determinantes nem demonstrar que o caso sob julgamento se ajusta àqueles fundamentos; dentre outras hipóteses enumeradas no art. 489, §1 ${ }^{\circ}$, I-VII.

Preocupou-se o legislador em estabelecer critérios racionais para evitar a mera reprodução de legislação, de jurisprudência ou de motivos "abstratos" que não estejam direta e fundamentadamente relacionados aos fatos do processo.

Veja-se que, pelo novo modelo do CPC/2015, a mera indicação, reprodução e paráfrase de ato normativo, sem que sua relação com a causa seja explicada, faz com que, objetivamente, a decisão judicial não seja considerada fundamentada. Porém, não há nenhuma previsão legislativa a respeito de qualquer ônus do juiz em fundamentar a escolha de algumas provas produzidas no processo, dentre as diversas provas porventura existentes em um mesmo processo. Encontra-se legislado que o juiz não pode se limitar a reproduzir um texto legislativo ou um enunciado de súmula, mas não há qualquer impeditivo de que deduza expressões tais como "a ocorrência do fato $F$ encontra-se provada pelo depoimento da testemunha A", mesmo quando haja uma série de outras provas e mesmo de outras testemunhas com depoimentos conflitantes no processo.

Nesse mesmo contexto, não há nada similar no sentido da valoração das provas em um contexto de multiplicidade de provas. Tomando como exemplo a prova testemunhal e a presença de três testemunhas, $\mathrm{A}, \mathrm{B}$ e $\mathrm{C}$, em que as testemunhas $\mathrm{A}$ e $\mathrm{C}$ afirmam que o fato jurídico em questão ocorreu e a testemunha B afirma que o fato não ocorreu. Não há qualquer

Rev. de Teorias da Justiça, da Decisão e da Argumentação Jurídica | e-ISSN: 2525-9644 | Porto Alegre | v. 4 | n. 2 | p. 71 - 87 | Jul/Dez. 2018 
regra explícita, dentro do modelo do livre convencimento motivado, que afirme que o juiz considerando, para o exemplo aqui proposto, apenas a existência de prova testemunhal - deve considerar que o fato ocorreu devido ao fato de ser narrado por uma maioria de testemunhas. Suponha-se que, no exemplo proposto, apenas a testemunha B contava com posição privilegiada (por exemplo, uma localização que facilitava a visualização de determinada ocorrência). Não existe um modelo racional que determine se o juiz deve considerar o depoimento da maioria das testemunhas ou daquela testemunha que tiver uma "aproximação" maior do fato a ser provado, sendo o juiz livre para utilizar a prova que, circunstancialmente, entender pertinente. O juiz pode até mesmo, em determinados contextos, considerar como suficientemente provados fatos acerca dos quais pesem notada controvérsia sobre sua ocorrência, bem como considerar como não suficientemente provados fatos acerca dos quais pese relevante e reconhecida carga probatória.

A situação tende a se agravar à medida em que a complexidade das questões fáticas aumenta. Imagine-se uma situação em que há vários elementos probatórios acerca de um mesmo fato, porém de forma divergente e mesmo contraditória, alguns apontando no sentido de provar a verdade do fato e outros no sentido de provar a falsidade do enunciado relativo ao mesmo fato. No caso, o juiz deverá escolher entre duas versões diferentes acerca do mesmo fato, ambas apoiadas por uma parte dos elementos probatórios constantes do processo.

No modelo vigente, o juiz não encontraria qualquer limite ou ônus normativamente previsto no sentido de fundamentar seu juízo acerca dos fatos, apontando que critérios utilizou para utilização de uma ou de outra prova, fundamentando por que considerou o fato provado em um ou outro sentido, podendo limitar-se a deduzir afirmações genéricas tais como "tendo em vista a Prova P1, considero provado que o fato F efetivamente ocorreu", sem qualquer menção às razões que levaram à eleição da prova $\mathrm{P} 1$ em detrimento de eventuais provas $\mathrm{P} 2$, $\mathrm{P} 3$, $\mathrm{P} 4$, etc. ou por que a prova $\mathrm{P} 3$, que apontava justamente no sentido contrário da prova P1 não foi considerada apta a interferir no convencimento judicial.

Knijinik (2001) aponta que a práxis brasileira orienta-se pela pura e simples renovação ou repetição do juízo de fato, como forma de efetuar controle do próprio juízo de fato: os tribunais brasileiros, quando do exame da quaestio facti, em geral reavaliam a prova como um todo, de modo que o mecanismo de controle da convicção judicial acaba reduzindose à sua própria renovação. Em outras palavras, o objeto do controle - a convicção judicial num segundo momento - o do recurso - transforma-se no próprio mecanismo de controle, 


\section{CONSTITUIÇÃO, EPISTEMOLOGIA E DECISÃO JUDICIAL: A NECESSIDADE DE CONSTRUÇÃO DE UM MODELO NORMATIVO DE FUNDAMENTAÇÃO DO JUÍZO DE FATO}

pois não se costuma examinar e verificar o iter lógico, a congruência narrativa, a consistência lógico -argumentativa do juízo de fato como uma questão 'in se', ou seja, como uma questão autônoma e relevante.

Como se disse, a disciplina da fundamentação da decisão judicial já evoluiu, no âmbito normativo, notadamente no Código de Processo Civil de 2015, no que diz respeito à fundamentação dos “juízos de direito”, já não mais se admitindo a mera remissão a artigos de lei, enunciados de súmula ou motivos que não se relacionem, fundamentadamente, ao feito. Mas em relação ao juízo de fato, surgem perplexidades tais como as acima exemplificadas, que chegam a fulminar diretamente a própria norma constitucional que exige a fundamentação da decisão judicial. Trata-se, sem dúvida, se uma grave anomalia em nosso sistema processual que o juízo de direito conte com parâmetros objetivos de aferição enquanto o juízo sobre os fatos seja relegado ao total arbítrio, favorecendo a irracionalidade das decisões e os erros judiciais.

Neves (1967, p. 586) é categórico em afirmar que, da questão de direito não é possível prescindir-se da solidária influência da questão de fato. Ou numa formulação bem mais expressiva para dizer a verdade, o "puro fato" e o "puro direito" não se encontram nunca na vida jurídica, não tendo o fato existência senão a partir do momento em que se torna matéria de aplicação do direito, e o direito, por sua vez, não tem interesse senão no momento em que se trata de aplicar o fato; pelo que, quando o jurista pensa o fato, pensa-o como matéria do direito, quando pensa o direito, pensa-o como forma destinada ao fato.

Tem-se que os esforços voltados à elaboração de um modelo normativo de fundamentação da decisão judicial, têm negligenciado a fundamentação do juízo de fato, que integra qualquer decisão judicial, como bem observam, por exemplo, Taruffo (1992, p. 47) e Atienza (2000, p. 315). A situação não é diversa, no que diz respeito ao tratamento de aspectos epistemológicos da prova judicial. Temas como o dos critérios (e os métodos lógicos) de valoração das provas, a determinação de standards probatórios a serem observados nessa atividade e outros assuntos correlatos receberam pouquíssima e ainda insipiente atenção, especialmente quando se compara à literatura anglo-americana.

Conforme Guerra (2006, p. 535-537), a doutrina processual brasileira não conta com uma tradição significativa de estudos em matéria probatória, especialmente no que diz respeito ao tratamento de aspectos epistemológicos da prova judicial. Um léxico insuficiente, deficitário, em matéria probatória seria um indicativo dessa deficiência, 
constituindo um obstáculo à sua superação, comprometendo a compreensão e o enfrentamento de importantes problemas em matéria probatória, notadamente os relacionados à justificação racional da decisão do juiz sobre os fatos da causa, o que o referido autor denomina dimensão epistemológica da prova judicial.

No entanto, a mera elaboração de um léxico adequado não é bastante para resolver os principais problemas em matéria probatória. Restam, ainda, outras duas fontes de dificuldades a se levar em consideração. Por um lado, verifica-se a insuficiência dos elementos normativos para fornecerem os parâmetros mínimos a serem observados na fundamentação do juízo de fato. Observa-se que há diversas normas no ordenamento que, direta ou indiretamente, disciplinam, em algum aspecto, a formação do convencimento judicial. Estas normas compõem a disciplina jurídica do convencimento judicial sobre fatos relevantes (o juízo de fato) e deveriam fornecer um modelo normativo de fundamentação do juízo de fato, mas se revelam insuficientes para tanto. Por exemplo, na disciplina jurídica do convencimento judicial não são explicitados critérios objetivos de valoração das provas. Da mesma forma, o problema do grau mínimo de confirmação de um determinado convencimento ou juízo de fato - o problema dos chamados standards probatórios - não recebe nenhum tratamento na mencionada disciplina jurídica.

Neste ponto, avulta a importância da epistemologia, especialmente no estabelecimento do método, do conjunto de modalidades com que são selecionadas, controladas e utilizadas as informações que servem para demonstração da veracidade das conclusões. As normas sobre as provas constituem um objeto natural de estudo em perspectiva epistemológica, visto que dizem respeito ao procedimento com que se apuram os fatos no processo.

\section{A CONSTRUÇÃO DE UM MODELO EPISTEMOLOGICAMENTE ADEQUADO}

É imprescindível que as construções referentes ao livre convencimento envolvam algum modelo de racionalidade capaz de oferecer critérios à valoração da prova. Além da devida fundamentação, a decisão sobre fatos em processos judiciais deve repousar sobre uma base epistemologicamente adequada, de forma a legitimar seu resultado. Nesse sentido, Silveira (2011, p. 24) aponta que o problema de valoração legítima da prova é, também o 


\section{CONSTITUIÇÃO, EPISTEMOLOGIA E DECISÃO JUDICIAL: A NECESSIDADE DE CONSTRUÇÃO DE UM MODELO NORMATIVO DE FUNDAMENTAÇÃO DO JUÍZO DE FATO}

problema da revisão de toda a sua dogmática, por que as considerações críticas feitas sobre esse tipo de raciocínio terão repercussões necessárias em seu aparelhamento.

Embora a epistemologia, que seria a principal fonte de subsídios capazes de sanar essas deficiências da disciplina jurídica relativa à formação racional do convencimento judicial sobre fatos relevantes (o assim chamado "juízo de fato"), também não se revele apta a, por si só, resolver esta complexa problemática, devido, em parte, ao fato de ser impossível identificar, atualmente, qual a teoria epistemológica predominante, não se pode prescindir de suas contribuições, ainda que conflitantes. Assim como não podem ser ignoradas as normas integrantes da disciplina normativa sobre o convencimento judicial, não se pode prescindir das contribuições da epistemologia. Mesmo que não exista uma hegemonia entre as principais teorias da epistemologia, é através de seu exame que se pode obter subsídios para a construção de um modelo normativo mínimo para a fundamentação do juízo de fato.

É extremamente profícuo debater sobre a função epistêmica do processo, considerando-o um conjunto estruturado de atividades com o fim de obter elementos de conhecimento verídicos sobre os fatos relevantes para a solução da controvérsia. Taruffo (2012, p. 160), destaca que a epistemologia representa uma das dimensões fundamentais para uma reconsideração atualizada do problema das provas. Reconhecidos epistemólogos ocupam-se dessa dimensão, aprofundando os temas da verdade e do erro nas decisões judiciais.

A revisão crítica das principais teorias epistemológicas sobre a justificação epistêmica, na perspectiva da disciplina normativa do juízo de fato, de modo a descartar aquelas que se revelem incompatíveis com a disciplina mencionada, bem como firmar as lições das teorias epistemológicas compatíveis com a disciplina normativa do juízo de fato e identificar, a partir daí, os elementos do ordenamento jurídico que podem servir de subsídio, podem contribuir substancialmente para a formação de um modelo normativo de fundamentação do juízo de fato.

A noção de justificação epistêmica é de grande valia para o estudo da fundamentação do juízo de fato, na medida em que constitui um conceito de avaliação epistêmica que deve respeitar gradações, de modo a permitir que um sujeito possa estar mais ou menos justificado ao crer que determinada proposição é verdadeira, exigindo o reconhecimento de gradações, que determinado sujeito pode estar mais ou menos justificado em crer o que quer que seja, e que o grau de justificação muda de acordo com as informações que o sujeito possui.

Rev. de Teorias da Justiça, da Decisão e da Argumentação Jurídica | e-ISSN: 2525-9644 | Porto Alegre |

v. 4 | n. 2 | p. 71 - 87 | Jul/Dez. 2018 
Justificação é algo que se pode adquirir, da mesma forma que se pode perder, tudo dependendo das informações ou evidências que um sujeito possui. Uma crença pode passar do estado de justificada para o de não justificada, relacionando-se diretamente com fundamentação da decisão judicial, especialmente no tema sob estudo, o juízo de fato. A análise de teorias tais como o fundacionalismo, o coerentismo, o funderentismo, o confiabilismo, o falibilismo, o pragmatismo e o relativismo, descartando, como já se afirmou, aquelas que se revelem incompatíveis com a disciplina mencionada, bem como firmar as lições das teorias epistemológicas compatíveis com a disciplina normativa do juízo de fato revela-se como a alternativa mais viável para o devido tratamento da questão analisada no presente artigo.

Da mesma forma, em todo e qualquer procedimento de caráter epistêmico, o método tem sensível importância, ou seja, o conjunto das modalidades com que são selecionadas, controladas e utilizadas as informações que servem para demonstrar a veracidade das conclusões. Conforme Taruffo (2012, p. 164), no âmbito do processo isso equivale a fazer referência sobretudo às regras que disciplinam a produção das provas e sua utilização. Por outro lado, um procedimento epistêmico válido requer que a determinação ou a criação dos elementos de conhecimento e das informações necessárias para a formulação de conclusões confiáveis sejam conhecidos e verificáveis, além de repetíveis, quando possível.

Ainda no contexto de uma "perspectiva epistêmica do processo", há o relevante aspecto dos sujeitos da atividade epistêmica, cujas posições podem ser problemáticas, haja vista que, no processo, embora este possa ser interpretado como um procedimento epistêmico, orientado no sentido da verdade dos fatos, seus sujeitos participantes buscam interesses diferentes e mesmo antagônicos e, ainda, podem não ser dirigidos no sentido da verdade dos fatos. As posições fundamentais que as partes assumem no que diz respeito às provas (e, assim, à decisão sobre os fatos) consistem na necessidade de satisfação do ônus da prova bem como no próprio direito à prova, que constitui uma das mais importantes garantias fundamentais. Do ponto de vista epistemológico, há a distinção entre a abordagem de quem tende a demonstrar uma tese e a abordagem de quem persegue de modo desinteressado a "descoberta da verdade", o que implicaria afirmar que a atividade das partes não pode ser posta no âmbito da dimensão epistêmica do processo. Mas só se pode chegar a essa conclusão, através do diálogo efetivo entre o Direito e a Epistemologia. 


\section{CONSTITUIÇÃO, EPISTEMOLOGIA E DECISÃO JUDICIAL: A NECESSIDADE DE CONSTRUÇÃO DE UM MODELO NORMATIVO DE FUNDAMENTAÇÃO DO JUÍZO DE FATO}

O diálogo entre Direito e epistemologia permite, num primeiro momento, que se supere as deficiências da disciplina jurídica do convencimento judicial sobre fatos relevantes. Disso resulta, todavia, um excesso de soluções, a ser devidamente eliminado com um exame das alternativas à luz de outros elementos do ordenamento jurídico. Com isso ter-se-á um modelo de fundamentação do convencimento judicial que leve na devida consideração os dados normativos e as teorias epistemológicas.

\section{CONCLUSÃO}

Diante das dificuldades expostas, tem-se como hipótese que as teorias epistemológicas e a fragmentária disciplina jurídica do convencimento judicial, se postas em contato, tendem a um "equilíbrio reflexivo": a partir da delineação da disciplina normativa relativa ao convencimento judicial, inclusive nos seus pontos falhos, e da revisão das principais teorias epistemológicas sobre a justificação epistêmica, é possível fazer uma apreciação dessas teorias, de modo a descartar aquelas que se revelem incompatíveis com a disciplina mencionada. As teorias remanescentes, por sua vez, permitem um significativo enriquecimento desta disciplina normativa e indicam os elementos posteriores do ordenamento jurídico, nomeadamente da ordem constitucional, que podem ser utilizados para construir um modelo mínimo de fundamentação do juízo de fato.

Dessa forma, este diálogo entre Direito e epistemologia permite, num primeiro momento, que as deficiências da disciplina jurídica do convencimento judicial sobre fatos relevantes sejam superadas. No entanto, disso resultaria um excesso de soluções, a ser devidamente eliminado com um exame das alternativas à luz de outros elementos do ordenamento jurídico. Com isso ter-se-á um modelo de fundamentação do convencimento judicial que leve na devida consideração os dados normativos e as teorias epistemológicas.

Levando-se em consideração a importância crucial da fundamentação das decisões judiciais para a realização de valores constitucionais da mais alta relevância, exsurge a necessidade de elaboração de um modelo normativo de fundamentação do juízo de fato, ou seja, o conjunto de critérios que devem ser seguidos pelo juiz na formação de seu convencimento sobre os fatos relevantes, em atendimento ao dever constitucionalmente imposto de fundamentação das decisões judiciais. Este conjunto de critérios também serve, obviamente, para avaliar se decisão já tomada observou ou não este dever. Ademais, diante da 
insuficiência e da indispensabilidade tanto das normas jurídicas relativas à matéria, como das teorias epistemológicas pertinentes para fornecerem tal modelo, justifica-se que a construção deste modelo se dê através de um profícuo diálogo entre Direito e Epistemologia.

Um modelo normativo de fundamentação do juízo de fato vem a ser ferramenta indispensável ao adequado cumprimento de uma das mais relevantes normas constitucionais, a saber: aquela que impõe a obrigatoriedade da fundamentação das decisões judiciais (CF, art. 93, IX). O correto atendimento desta exigência, repita-se, é imprescindível para que se possa, entre outras coisas, aferir o respeito a outros valores constitucionais fundamentais, tais como a legalidade, a imparcialidade do juiz, o contraditório e outros. Além disso, o modelo serve, sem dúvida, para incrementar a racionalidade das decisões judiciais em matéria probatória, por servir aos operadores jurídicos como instrumento da análise crítica de tais decisões e a consequente consolidação de uma cultura de elevada racionalidade judicial.

\section{REFERÊNCIAS}

ATIENZA, Manuel. As Razões do Direito - Teorias da Argumentação Jurídica. Maria Cristina Guimarães Cupertino (trad.), São Paulo: Landy Ed., 2000.

GUERRA, Marcelo Lima. Notas sobre o dever constitucional de fundamentar as decisões judiciais. In ARRUDA ALVIM WAMBIER, Teresa, FUX, Luiz e NERY Jr., Nelson (Coords.) Processo e Constituição - Estudos em Homenagem ao Professor José Carlos Barbosa Moreira.. São Paulo: RT, 2006.

. Premissas para a construção de um léxico constitucional epistemologicamente adequado em matéria probatória (disponível em http://www.publicadireito.com.br/conpedi/manaus/arquivos/anais/fortaleza/4060.pdf)

HAACK, Susan. Evidence and Inquiry. A Pragmatist Reconstruction of Epistemology. 2a. ed. Amherst: Prometheus Books, 2009.

KNIJINIK, Danilo. A prova nos juízos cível, penal e tributário. Rio de Janeiro: Forense, 2007.

$$
\text { . OS “STANDARDS” DO CONVENCIMENTO JUDICIAL: }
$$

PARADIGMAS PARA O SEU POSSÍVEL CONTROLE. 2001. Disponível em http://www.abdpc.org.br/abdpc/artigos/Danilo\%20Knijnik\%20-\%20formatado.pdf 


\section{CONSTITUIÇÃO, EPISTEMOLOGIA E DECISÃO JUDICIAL: A NECESSIDADE DE CONSTRUÇÃO DE UM MODELO NORMATIVO DE FUNDAMENTAÇÃO DO JUÍZO DE FATO}

MIRANDA, Pontes de. Tratado de Direito Privado, I. Rio de Janeiro: Borsói, 1954.

NEVES, Antonio Castanheira. Questão-de-facto e questão-de-direito. O problema metodológico da juridicidade (ensaio de uma reposição crítica). Coimbra: Almedina, 1967, p. 586.

SILVEIRA, Daniel Coutinho da. Prova, Argumento e Decisão. Critérios de suficiência para orientação dos juízos de fato no direito processual brasileiro. 2011. Dissertação (Mestrado em Direito) Faculdade de Direito da Universidade de São Paulo.

TARUFFO, Michele. A prova. Tradução de João Gabriel Couto. São Paulo: Marcial Pons, 2014.

Uma simples verdade. $O$ juiz e a construção dos fatos. Tradução de

Vitor de Paula Ramos. Madrid: Marcial Pons, 2012. 